\title{
Objetos de aprendizagem aplicados no ensino fundamental em época de pandemia: relatos de experiências com dispositivos móveis em sala de aula remota
}

Fabrícia Damando Santos*, Michele Moscardini de Farias Lopes*, Aline Gonçalves de Farias Fagundes ${ }^{* * *}$, Gladis Falavigna ${ }^{* * * *}$, Luciano Andreatta-da-Costa ${ }^{* * * *}$

\section{Resumo}

Este artigo descreve a utilização dos objetos de aprendizagem como recurso didático no ensino fundamental em tempos de pandemia. Foram realizadas lives para professores das redes de ensino, atingindo um total de 571 docentes. Utilizou-se como metodologia um grupo focal formado por 12 professores. Foi constatado que o uso do celular como recurso pedagógico é ainda incipiente, além da importância do acompanhamento familiar. O custo do acesso à internet, bem como o uso apenas ao final do dia, estão entre as limitações encontradas. Conclui-se que a cultura digital precisa ser incentivada nas escolas, ampliando as possibilidades de sucesso de experiências em ensino remoto.

Palavras-chave: Objetos de aprendizagem; Aprendizagem a partir de dispositivos móveis; Tecnologias para Educação

\footnotetext{
Doutora em Informática da Educação pela Universidade Federal do Rio Grande do Sul (UFRGS). Docente e Coordenadora Adjunta do Programa de Pós-Graduação em Formação Docente para Ciências, Tecnologias, Engenharias e Matemática (PPGSTEM/ UERGS). Brasil. E-mail: fabricia-santos@uergs.edu.br

** Mestranda em Formação Docente para Ciências, Tecnologias, Engenharias e Matemática (PPGSTEM/UERGS). Brasil. E-mail: michele-lopes@uergs.edu.br

*** Mestranda em Formação Docente para Ciências, Tecnologias, Engenharias e Matemática (PPGSTEM/UERGS). Brasil. E-mail: aline-fagundes@uergs.edu.br

**** Doutora em Educação. Docente do Programa de Pós-Graduação em Formação Docente para Ciências, Tecnologias, Engenharias e Matemática (PPGSTEM/ UERGS). Brasil. E-mail: gladis-falavigna@uergs.edu.br

***** Doutor em Engenharia Civil pela UFRGS, no tema da Educação em Engenharia. Coordenador e docente do Programa de Pós-Graduação em Formação Docente para Ciências, Tecnologias, Engenharias e Matemática (PPGSTEM/ UERGS). Brasil. E-mail: luciano-costa@uergs.edu.br
} 


\section{Introdução}

Nos últimos anos a quantidade de recursos tecnológicos específicos para a educação tem tido um aumento significativo, principalmente devido ao apoio que esses recursos têm dado ao processo de ensino e aprendizagem. $\mathrm{O}$ incremento de profissionais mais qualificados para este desenvolvimento também contribuiu com este cenário. Consideramos como

[...] materiais educacionais desde jogos educacionais, simuladores, aplicativos específicos para determinados componentes curriculares, softwares para o apoio no desenvolvimento do pensamento computacional, vídeos, imagens, até museus digitais, animações, dentre outros (BRAGA; MENEZES, 2015).

Todavia, observa-se que boa parte desses recursos não são utilizados nas atividades docentes de forma frequente. Schuhmacher et al. (2016) apontam "as limitações resultantes dos baixos resultados de inserção curricular de propostas que utilizam as tecnologias em educação, na perspectiva do professor, mesmo que ele considere tal utilização importante."

Diante da necessidade iminente em realizar aulas de forma remota na rede municipal e estadual, durante a suspensão das aulas devido à pandemia do COVID-19, muitos professores tiveram que se reinventar, se adaptar e traçar formas de atender aos seus alunos, tendo um novo desafio e também uma nova oportunidade. Cresceu tanto o interesse quanto a demanda por uma rede de apoio aos profissionais da educação para o uso de novas tecnologias em sala de aula para apoiar o ensino. Ao analisar a necessidade escolar e observar os recursos disponíveis dos alunos e professores que permitisse comunicação de forma mais rápida e sem custos, percebeu-se que o celular poderia ser um aliado nesse momento.

Segundo o levantamento realizado pelo Instituto Brasileiro de Geografia e Estatística (IBGE), "o celular é o equipamento mais usado para o acesso à internet em cerca de 98,7\% dos domicílios brasileiros que possuem acesso à internet” (IBGE, 2017). Em uma pesquisa feita pela Fundação Getúlio Vargas (FGV), no Brasil há mais de um smarthphone ativo por pessoa. Usar o celular como apoio ao ensino já é algo realizado há algum tempo, e é conhecido como Mobile Learning, ou simplesmente, $M$-Learning. "O M-Learning é uma modalidade de ensino onde dispositivos móveis são usados como apoio ao processo de ensino e aprendizagem” (OLIVEIRA et al., 2014). 
Além disso, vale ressaltar que a Base Nacional Comum Curricular (BNCC), documento normativo criado para buscar um equilíbrio em toda a rede de ensino básico, apresenta a competência denominada cultura digital, "estabelecendo a necessidade em compreender, utilizar e criar tecnologias digitais de informação e comunicação para se comunicar, acessar e disseminar informações, produzir conhecimentos, resolver problemas" (BRASIL, 2018). A partir dessa nova perspectiva, a cultura digital é um item de alta relevância, pois constitui uma das competências a serem trabalhadas pelas escolas. Considerando esse importante documento nacional, alguns pontos geram inquietação, como por exemplo: os nossos professores, em sua maioria, estão preparados para a inserção de novas tecnologias baseadas no uso de objetos de aprendizagem através dos dispositivos móveis em seus planejamentos, para contemplar a competência geral da cultura digital?

A partir dessa questão, o presente trabalho teve como objetivo apresentar aos professores possibilidades de uso do celular como ferramenta de apoio ao ensino de forma remota, sendo usado tanto a ferramenta WhatsApp ${ }^{1}$ como meio para fomentar a comunicação entre professor e aluno, bem como a apresentação de OA como aplicativos, para serem utilizados nos diversos componentes curriculares escolares.

Essa possibilidade resultou em um curso intitulado por "Uso de Objetos de Aprendizagem (OA) na educação infantil, nos anos iniciais e finais do ensino fundamental: dicas de aplicativos e formas de utilização", o qual foi ofertado aos professores de escolas estaduais e municipais, acompanhado por um período de 2 meses, após a realização do curso, a fim de fomentar o M-Learning em sala de aula remota.

O presente artigo está estruturado em Seções, onde na primeira é apresentada a introdução, a Seção 2 discorre sobre objetos e aprendizagem, a Seção 3 aborda o uso do M-Learning da educação, os trabalhos relacionados estão relatados na Seção 4, a metodologia e análise dos resultados são apresentados na Seção 5, na Seção 6 há uma discussão sobre o grupo focal e análise dos resultados obtidos e, por fim, as considerações finais estão presentes na Seção 7.

\section{Objetos de Aprendizagem}

Pensando em auxiliar o ensino e aprendizado dos alunos visando a compreensão de conceitos mais complexos atrelado ao avanço tecnológico atual, contemplando a $\mathrm{BNCC}$, os objetos de aprendizagem (OA) apresentam-se como ferramenta de 
aprendizagem e orientação, a qual pode ser adaptada, reutilizada e aprimorada devido a sua flexibilidade. Segundo Aguiar e Flôres (2014, p.12), os "OAs podem ser apresentados em qualquer meio de comunicação e de difusão de informações ou apresentados em formatos diferenciados". Sua característica de reuso, bem como a sua apresentação em módulos, faz com que sua utilização seja apreciada por professores e alunos. No entanto, a metodologia aplicada com o qual o OA será utilizado, constituirá determinantemente para que o ensino e a aprendizagem do aluno se tornem eficaz considerando os objetivos que se quer alcançar e as habilidades que se quer desenvolver.

Wiley (2000), agrega a sua definição de OA e acrescenta, dando ênfase para a intencionalidade na finalidade de sua utilização quanto ao processo de ensino e aprendizagem.

Neste artigo, por se tratar de uma proposta de cunho pedagógico, optou-se por apresentar a classificação realizada por Behar e Torezzann (2013), a qual os objetos de aprendizagem são classificados em três categorias: simples, intermediário e complexo. São considerados OAs simples, textos, imagens, mapas conceituais e outros que requerem pouca interação do usuário. Os considerados intermediários são, em sua maioria, midiáticos, como vídeos, músicas e sites de informação. Possuem ainda uma interação limitada e apresentam-se, na maioria das vezes, como fonte de informação. Já os de classificação complexa, constituem-se da união dos objetos de aprendizagem considerados simples e intermediários, formando uma singularidade, com maior interação e interatividade entre o usuário e o objeto, tendo como exemplo os aplicativos, simulações e animações.

Incluir a cultura digital na escola, principalmente, no ensino remoto de forma emergencial, é uma realidade em potencial para uma gama de escolas, às quais nunca usaram ambientes virtuais de aprendizagem e se depararam com uma realidade iminente, onde a maioria dos alunos não possuem computadores e nem internet em casa. A alternativa que mais se mostra viável é o uso do celular, pois o mesmo já é usado por meio do M-Learning, juntamente com a recomendação de aplicativos para apoio no processo de ensino e aprendizagem. Através do celular é possível usar alguns aplicativos para apoio nas atividades remotas. 


\section{M-Learning}

A popularização dos dispositivos móveis na última década como celulares, smartphones, MP4, netbooks, notebook, tablets, dentre outros, tem se mostrado que a presença desses dispositivos na sociedade permite maior conectividade entre as pessoas. Da mesma forma, a melhoria dos serviços de internet e sua cobertura também tem crescido nos últimos anos. Esses dispositivos móveis, com o passar dos anos, começaram a ser usados com finalidades educacionais (SACOOL; SCHLEMMER; BARBOSA, 2011).

Acessar, via dispositivos móveis, os mundos virtuais, ambientes virtuais de aprendizagem, usar jogos educacionais e, até mesmo, podcasts, é algo factível atualmente podendo ser usado para a aprendizagem. É nesse sentido que os autores Sacool, Schlemmer e Barbosa (2011) "apresentam iniciativas suportadas com o uso de dispositivos móveis para maximizar experiências de aprendizagem, tanto presenciais, quanto remotas, dando destaque importante à possibilidade da mobilidade."

Muitos autores registram suas observações e pesquisas sobre as novas combinações das tecnologias digitais como Blended Learning ou B-Learning para o século XXI. Monteiro, Moreira e Lencastre (2015, p. 17) relatam que

[...] nos últimos dez anos as experiências de educação e investigação em blended learning aumentaram significativamente, fruto dos desenvolvimentos tecnológicos e como resultados das diferentes iniciativas para inovar pedagogicamente integrando as TIC nos sistemas de ensino.

Os autores discutem qual é a função do B-Learning, sua importância para a educação, assim como os aspectos positivos e negativos dessa aprendizagem híbrida.

Sacool, Schlemmer e Barbosa (2011) abordam que, "a aprendizagem em um contexto de mobilidade potencializa o aprender, justamente pela maleabilidade do tempo e espaço, devido à troca de ideias e informações, socialização de conhecimentos.” Já estamos há algum tempo presenciando o avanço do M-Learning na educação, sem muitas propostas oficiais educacionais, porém, no momento de pandemia do COVID-19, talvez seja a oportunidade de acertar esse diálogo com as novas tecnologias.

Ao mesmo tempo em que o M-Learning avança, Silva e Falavigna (2017) destacam a necessidade da formação e concepção dos docentes para o uso das tecnologias móveis na sala de aula. As autoras ainda relatam que 
[...] ao contrário do que normalmente se tem feito, ao invés de retirar dos alunos as tecnologias móveis em sala de aula, evitando o uso do celular, por exemplo, o recomendável seria pensar no bom uso dessas tecnologias numa atividade específica de determinado conteúdo tratado em aula.

\section{Trabalhos relacionados}

Neste tópico, são apresentadas algumas pesquisas envolvendo uso de objetos de aprendizagem, na aprendizagem bem como o uso de aplicativos em sala de aula e suas implicações no ensino.

O trabalho de Oliveira et al. (2014) aborda experiências realizadas com M-Learning em cursos a distância, onde o uso do WhatsApp foi utilizado inicialmente na discussão de grupos. Durante cinco semanas os grupos formados nessa ferramenta funcionaram como um fórum de discussão, onde há a possibilidade de se compartilhar textos, mensagens de áudio, vídeo, links, etc. Após esse período, os autores propuseram um curso para capacitação de professores e tutores onde relataram aumentando das relações pessoais entre os membros do grupo e a sensação de comunidade e colaboração do mesmo.

Na pesquisa de Santos, Lima e Wives (2010) a união entre dispositivos móveis e objetos de aprendizagem, ocorreu por meio do recurso de QR-Code para acessar conteúdos educacionais na TV digital. Através de um papel o aluno consegue interagir com o OA usando um dispositivo móvel. Ao escolher uma opção (representada por QR-Code), o OA executa a ação e exibe a animação correspondente. Os autores usaram a área de matemática, mais especificamente sobre grandezas proporcionais, conteúdo apresentado na $6^{\mathrm{a}}$ série do ensino fundamental, criaram o QR-code e o OA para permitir a animação, apresentando uma proposta inicial como alternativa para acesso ubíquo a conteúdos educacionais. Mesmo sendo um trabalho mais antigo, se mostra atual.

O estudo de Hitzschky et al. (2018), buscou investigar as influências da utilização de aplicativos educacionais na formação de professores no Ensino Fundamental, em três etapas respectivas: o levantamento de aplicativos direcionados à Língua Portuguesa e Matemática, a catalogação destes dispositivos e a formação de professores, por meio de oficinas. Com a intenção de articular a teoria e prática, no contexto proposto e a seleção pelos professores participantes da formação, gerou a elaboração de planejamentos pedagógicos com o uso desses aplicativos educacionais 
selecionados e sua aplicação. Ao final observou-se por meio dos relatos, uma adesão significativa desses recursos, a importância das formações continuadas e a troca de experiências bem sucedidas.

\section{Metodologia}

A presente pesquisa possui natureza aplicada, com abordagem exploratória. Para apresentação dos resultados, foi realizada uma análise quanti-qualitativa dos dados, utilizando o procedimento de grupo focal pelo método de associação livre. Participaram da pesquisa professores oriundos das diversas redes de ensino, onde $81 \%$ dos professores são da rede municipal, $14 \%$ da rede estadual $14 \%$ e $5 \%$ de escolas particulares. Sobre os professores, cerca de $65 \%$ nunca tinham utilizado aplicativos em sala de aula com objetivo de apoio no ensino.

Como a proposta do presente trabalho foi apresentar aos professores possibilidades de uso do celular como ferramenta de apoio ao ensino de forma remota, foi desenvolvido e aplicado um curso para professores interessados. Este curso teve duração de 5 dias, com 2 horas por dia, sendo realizado no formato de lives com inscrição prévia. Se inscreveram cerca de 571 professores da educação infantil e ensino fundamental. Durante os cinco dias, foram realizadas lives para a educação infantil (live do primeiro dia), uma live para $1^{\circ}$ e $2^{\circ}$ anos (live do segundo dia), outra live para $4^{\circ}$ e $5^{\circ}$ anos, por fim, a live dos $6^{\circ}$ ao $9^{\circ}$ anos. As lives ocorreram de forma diária, síncronas, via google meet(ferramenta do Google para videoconferência), entre os dias 20/04/2020 e 24/04/2020, sempre às $14 \mathrm{~h}$. Todos os participantes receberam, antecipadamente, o convite com o link para entrar do curso e só participava quem estava inscrito na mesma. Cada uma dessas lives estão disponíveis no canal do youtube.

\section{Atividade realizada}

Durante os cinco dias de curso/lives, foram expostos o conceito de objetos de aprendizagem, suas formas de utilização em sala de aula, bem como exemplos aplicados na aprendizagem. Foram selecionados uma série de aplicativos, os quais foram recomendados a serem usados em componentes curriculares, dicas de uso 
e atividades possíveis, formas de indicar aos alunos e como trabalhar com esses alunos o M-Learning.

As lives com os docentes interessados no tema da educação infantil, voltado à crianças de 4 e 5 anos, teve como foco central da exploração da ludicidade, através da interação com alguns aplicativos (app), que promovam a musicalidade, atenção, a contagem e os sons das letras. Para este momento foram sugeridos 14 itens entre canais de vídeos e aplicativos.

No segundo dia, o momento foi destinado aos professores interessados as propostas voltadas ao $1^{\circ}$ e $2^{\circ}$ anos do ensino fundamental. $\mathrm{O}$ objetivo principal foi a alfabetização e as questões de sequenciamento numérico, contagem e quantificações. Foram apresentadas 24 sugestões, destas 4 eram voltadas a língua portuguesa e 4 às questões matemáticas.

A live voltada aos educadores interessados às práticas para os $3^{\circ}$ anos do ensino fundamental, teve como foco a consolidação da escrita e o término do ciclo de alfabetização. Na ocasião, foram apresentadas 30 sugestões de aplicativos, 3 aplicativos voltados à leitura e contação de histórias, juntamente com outros 5 para língua portuguesa, 4 aplicativos para matemática envolvendo as quatro operações fundamentais, além de jogos dos 7 erros, quebra-cabeças e um aplicativo de desenvolvimento do pensamento computacional como o scratch júnior.

Aos docentes que buscavam sugestões para turmas de $4^{\circ}$ e $5^{\circ}$ anos do ensino fundamental, buscou-se contemplar outras áreas do conhecimento, explorando Ciências, Geografia e idiomas. Foram sugeridos 39 aplicativos, sendo 7 deles para matemática contendo cálculos, sequências, desafio de lógica, 8 aplicativos que englobam jogos diversos que estimulam o raciocínio lógico, a resolução de problemas, tomada de decisões, 5 aplicativos para língua portuguesa a fim de aprimorar a ortografia e o repertório de palavras e 3 voltados ao desenvolvimento do pensamento computacional.

Por fim, na última live destinada aos professores interessados, aos anos finais do fundamental, do $6^{\circ}$ ao $9^{\circ}$ ano. A capacitação sugeriu 37 itens, destes 2 canais de conhecimento variado e um de experimentos, 8 aplicativos de matemática destacando o Geogebra ${ }^{2}$ e o PhotoMath ${ }^{3}, 3$ itens para língua portuguesa que tratam de regras gramaticais, questões ortográficas, destaque para o dicionário Aurélio Digital. Além de aplicativos de Química, linguagem de programação, idiomas, Geografia, História, Filosofia, Artes, conhecimentos variados, jogos, plataformas para os pro- 
fessores desenvolveram aulas, opções de ferramentas que possibilitam a criação de um ambiente interativo, entre alunos e professores, sem precisar instalar nenhum aplicativo, bem como aplicativos voltados ao autismo.

Aproximadamente um mês após o término das lives, os professores foram convidados a participar de uma pesquisa de satisfação, onde uma das questões buscava identificar o grau de satisfação dos participantes com as lives desenvolvidas. Esse grau de satisfação foi delimitado em uma escala likert de 1 a 5 , sendo 1 (insatisfeito) e 5 (muito satisfeito). Cerca de $78 \%$ responderam que ficaram muito satisfeitos e $21 \%$ satisfeitos, levando a considerar que a escolha e seleção dos aplicativos apresentados estavam adequados com os devidos componentes curriculares e com cada ano escolar.

Outro questionamento realizado, dizia respeito à anterior utilização de algum aplicativo sugerido em suas práticas didáticas. $35 \%$ responderam que já estavam usando algum aplicativo sugerido. Observa-se que, em um curto espaço de tempo, alguns professores já estavam colocando em prática os aplicativos sugeridos, bem como uso mais efetivo do M-Learning em aula remota, atestando a importância da capacitação docente em tempos de pandemia. Diante desses resultados, após 60 dias da realização do curso, propomos um grupo focal para troca de experiências acerca do uso de dispositivos móveis em sala de aula.

\section{Grupo focal e análise dos resultados}

Após um determinado período em que as lives ocorreram, os professores, sujeitos da pesquisa, foram convidados a participar de um um grupo focal sobre experiências em sala de aula com o uso dos aplicativos e dispositivos móveis, dessa forma seria possível compartilhar experiências e permitiria a análise dos resultados das lives e uso dos aplicativos em sala de aula.

A utilização do grupo focal permite a obtenção de informações por meio de uma questão de estudo, possibilitando uma comunidade de interação, permitindo aos participantes se expressarem mais do que em uma entrevista individual (FLICK, 2013). O grupo focal foi realizado no mês de junho/2020, após dois meses de realização das lives com os professores, tempo considerado adequado para que houvesse alguma aplicação dos aplicativos sugeridos em sala de aula. O grupo focal teve a participação de 12 professores e pesquisadores do presente trabalho. Como o grupo 
era homogêneo, não foi realizada a divisão grupal e a moderação se deu de forma substancial, introduzindo algumas perguntas. A reunião com o grupo focal ficou gravada e está disponível para acesso e acompanhamento. Alguns relatos foram transpostos, bem como algumas percepções do grupo focal.

A pergunta inicial foi sobre as experiências com os dispositivos móveis em sala de aula por meio dos aplicativos sugeridos. Os participantes relataram, em sua maioria, que estão usando o WhatsApp para comunicação com os alunos, formando grupos em cada turma. Nesses grupos, estão presentes os alunos, os pais, a supervisão da escola e a professora da turma, sendo esta, uma sugestão apresentada durante o curso realizado.

Uma professora de séries iniciais, destacou que praticamente não conhecia aplicativos possíveis de serem utilizados na aprendizagem e que os aplicativos sugeridos ela simplesmente os recomendou aos pais para serem baixados e mostrados aos alunos. Não realizou atividades específicas para serem trabalhadas com esses aplicativos sugeridos.

Há pontos importantes levantados e discutidos pelas professoras no que diz respeito ao acesso dos alunos, tanto ao aparelho celular quanto à internet, relatando que apesar de terem celular em casa, o pacote de dados da maioria dos alunos (escolas públicas) é limitado, fato que dificulta o uso do celular quando é preciso baixar um aplicativo, ou ter um vídeo para explicar ao aluno como trabalhar com aplicativo em casa. Por outro lado, há uma dependência que uma criança do ensino fundamental tem dos pais para acessarem as atividades remotas, via celular, o que muitas vezes limita a atividade de ensino.

Alguns relatos apontam situações específicas, como o relato da professora A: "professores da minha idade já se sai melhor com relação aos aplicativos, muitos professores não conseguem nem usar o computador, fazer um power point, fazer um jogo”. A professora relata a realidade dos alunos da escola, que é uma escola pública, onde os alunos apesar de terem o celular em casa, há pouco retorno das atividades solicitadas aos mesmos.

Relato da professora B:

[...] eu percebo que as atividades encaminhadas estão ficando poucas, que preciso aprender a utilizar os aplicativos para que eles se interessem, porque a gente nunca precisou tanto como agora. Além disso, há uma resistência dos pais em reconhecer que algumas atividades que estavam sendo enviadas de forma eletrônica, o filho não iria aprender. Que eles não aprendem com os jogos. 
$\mathrm{Na}$ fala dessa professora, também fica evidente que os pais acreditam que usar um aplicativo ou jogo no celular aplicado no ensino, parece ser um momento de distração e não de aprendizagem.

Relato da supervisora sobre a percepção de algumas famílias: "Com um aplicativo, alguns pais acham que o filho aprende menos pois não estão copiando". Esse tipo de raciocínio dos pais, quando a escola apresentou a possibilidade de trabalhar com celulares em aulas remotas, reflete a importância da escola mostrar o quão importante pode ser um aplicativo ao ser usado para apoio na aprendizagem, como a tecnologia e o uso de materiais educacionais digitais e OA podem fazer usados para aprender.

Relato da professora C: "O retorno do aluno via tecnologia é mais rápido, porém, obtive maior retorno dos alunos quando usei outros objetos de aprendizagem que não fossem aplicativos". Essa professora trabalha com uma turma de alunos com dificuldades de aprendizagem como dislexia, discalculia, dentre outras. Desenvolve as atividades de forma síncrona, permitindo uma maior interação com os alunos, usou alguns aplicativos e usa em momentos síncronos outros softwares com seus alunos.

A professora $\mathrm{D}$, relatou que utilizou um aplicativo para permitir que o aluno trabalhasse com sílabas, explorou várias sílabas em várias atividades. Esta professora utilizou aplicativo com os alunos e obteve um retorno satisfatório.

De forma geral, em algumas turmas, as professoras tiveram retorno de atividades usando celular com cerca de no máximo $70 \%$ dos alunos no início da pandemia, referente ao final do primeiro semestre. Porém, por volta de julho e agosto, os retornos dos alunos ficaram em torno de $20 \%$. Essa diminuição de retorno das atividades propostas via celular, pode se dar pelo envolvimento da família com as atividades escolares mas, também, por problemas de acesso como falta de internet no celular. Muitas professoras relataram que as famílias que são mais presentes na educação escolar dos filhos, os retornos das atividades são mais frequentes.

\section{Considerações finais}

Este estudo foi derivado a partir de uma série de lives sobre o uso de objetos de aprendizagem e de dispositivos móveis na educação. Porém, nesse momento de pandemia do COVID-19, escolas e professores foram pegos de surpresa e buscaram 
alternativas para continuar com as atividades escolares. Uma das alternativas poderia ser o uso de OA, aplicativos e uso de dispositivos móveis em sala de aula. Muitos desses professores estão se capacitando, redes estaduais, municipais e particulares estão buscando formas de atender os alunos. Uma das alternativas sugeridas foi o uso do celular, pois é um dispositivo de mais fácil acesso tanto pelas famílias quanto aos próprios alunos.

Diante da necessidade de capacitação urgente, a presente pesquisa propôs um curso em forma de lives para professores, onde várias sugestões foram apresentadas, mostrando OA e aplicativos que pudessem ser usados em sala de aula. Após esse curso ser realizado por 571 professores, buscou-se saber como eles estavam trabalhando com seus alunos. Muitos benefícios e limitações foram apontados pelos professores, principalmente, os de escolas públicas. Apesar do levantamento realizado pelas escolas indicarem que praticamente todas as famílias possuíam pelo menos um aparelho celular, o seu uso efetivo como apoio ao ensino ainda se mostra incipiente. Algumas situações relatadas como falta de pacote de dados para acesso à internet, acesso ao celular somente ao final do dia quando o responsável estava em casa e, até mesmo, atividades bem planejadas para serem usadas, ainda precisam de melhorias.

Percebe-se que deve ser trabalhada a conscientização das famílias sobre o fato de que as atividades enviadas eletronicamente e o uso de aplicativos são usados no processo de ensino e aprendizagem, evidenciando o potencial em que um aplicativo pode apoiar na aprendizagem do aluno deve ser explícito para as famílias.

Por outro lado, há uma necessidade iminente de um letramento digital e da cultura digital nas escolas, tanto para professores quanto para as famílias. Apesar dos professores estarem buscando capacitações, é notório que ainda falta muita formação docente para que os mesmos usem tecnologias digitais de informação em suas salas de aula, saibam explorar efetivamente o M-Learning, conheçam e produzem OA e diversos materiais digitais educacionais. 


\section{Learning objetcs applied in elementary education during a pandemic period: reports of experiences with a mobile devices in a remote classroom}

\section{Abstract}

This paper describes the use of learning objects as a teaching resource in elementary education in times of pandemic. Conferences were made for teachers, reaching a total of 571 participants. We used as methodology a focus group formed by 12 teachers. It was found that the use of cell phones as educational resources is still incipient, in addition to the importance of family monitoring. The cost of Internet access, as well as use only at the end of the day, are among those restrictions of this research. We conclude that digital culture needs to be encouraged in schools, thus expanding the possibilities for successful remote education.

Keywords: Learning objects; M-learning; Technology for education.

\section{Notas}

1 WhasApp é um aplicativo de mensagens usado em várias plataformas, bastando ter um smarthphone e internet.

2 https://www.geogebra.org/?lang=pt

3 https://photomath.net/pt/

\section{Referências}

AGUIAR, Eliane Vigneron Barreto; FLÔRES, Maria Lucia Pozzatti. Objetos de Aprendizagem: conceitos básicos. In: Objetos de Aprendizagem: teoria e prática. Porto Alegre: Evangraf, 2014.

BEHAR, Patricia Alejandra; TORREZZAN, Cristina Alba Wildt. Competências para a construção de materiais educacionais digitais baseados no design pedagógico. In: Behar, P. (org) Competências em educação a distância, Porto Alegre: Penso, 2013.

BRAGA, Juliana; Menezes, LILIAN. Introdução aos objetos de aprendizagem. In: Objetos de Aprendizagem Volume 1: introdução e fundamentos. Santo André: UFABC, 2015.

BRASIL. Ministério da Educação. Base Nacional Comum Curricular. Brasília, 2018.

FLICK, Uwe. Uma introdução à metodologia de pesquisa: um guia para iniciantes. Porto Alegre: Penso, 2013.

HITZSCHKY, Rayssa Araújo; ARRUDA Juliana Silva; LIMA, Cintia Arruda; SIQUEIRA, Liliane Maria Ramalho de Castro; FILHO, José Aires de Castro; O uso de aplicativos educacionais no Ensino Fundamental em tempos de aprendizagem móvel: contribuições para a formação de professores. Revista Tecnologias na Educação - Ano 10 - Número/Vol.26, p. 113-134, 2018. 
IBGE. Dados sobre o acesso a internet no Brasil, 2017. Disponível em: https://educa.ibge. gov.br/jovens/materias-especiais/20787-uso-de-internet-televisao-e-celular-no-brasil.html, em 3 de abril de 2020.

MOREIRA, António; MONTEIRO, Angelica; LENCASTRE, José Alberto. Blended (E) Learning na sciedade digital: dinâmicas educacionais contemporâneas. Coleção Estudos Pedagógicos. 1ª Edição, Santo Tirso, Portugal, 2015.

OLIVIERA, Estêvão Domingos Soares de; SOUSA, Hercilio de Medeiros; ANJOS, Eudisley Gomes dos; JUNIOR, Jose Jorge Lima Dias; LEITE, Jan Edson Rodrigues; OLIVEIRA, Felipe Soares de. Experiência do uso do Whatsapp como Ambiente Virtual de Ensino e Aprendizagem em um Curso a Distância. 3ำ Congresso Brasileiro de Informática na Educação. 20ª Workshop de Informática na Escola WIE, 2014.

SACCOL, Amarolinda; SCHLEMMER, Eliane; BARBOSA, Jorge. M-learning e u-learning: novas perspectivas das aprendizagens móvel e ubíqua. São Paulo: Pearson Prentice Hall, 2011.

SANTOS, Núbia dos Santos Rosa Santana dos; LIMA, José Valdeni de; WIVES, Leandro Krug. Integração de recursos para acesso aos Objetos de Aprendizagem Multimodais. RENOTE. Revista Novas Tecnologias na Educação, v. 10, p. 1-10, 2012. DOI: https://doi.org/10.22456/16791916.36394

SCHUHMACHER, Vera Rejane Niedersberg; SCHUHMACHER, Elcio; OLIVEIRA, Lia Raquel Moreira; COUTINHO, Clara Pereira. A percepção do professor sobre suas competências em tecnologias da informação e comunicação. Revista Novas Tecnologias na Educação, Pós Graduação em Ensino de Ciências Naturais e Matemática. Porto Alegre, V. 14, № 1, julho, 2016. DOI: https://doi.org/10.22456/1679-1916.67370

SILVA, Bento Duarte da.; FALAVIGNA, Gladis. (ORG). Sonhos Realizados: Resenhas das Dissertações de Mestrado dos estudantes de São Francisco de Paula/RS. Porto Alegre: EDIPUCRS, 2017.

WILEY, David.Connecting learning objects to instructional design theory: A definition, a metaphor, and a taxonomy, 2000. Disponível em http://www.reusability. org/. Acesso em 05 jun, 2020. 